\title{
On the binding of complement to solid artificial surfaces in vitro
}

\author{
Jonas Wetterö, Agneta Askendal, Torbjörn Bengtsson and Pentti Tengvall
}

\section{Linköping University Post Print}

N.B.: When citing this work, cite the original article.

Original Publication:

Jonas Wetterö, Agneta Askendal, Torbjörn Bengtsson and Pentti Tengvall, On the binding of complement to solid artificial surfaces in vitro, 2002, Biomaterials, (23), 4, 981-991.

http://dx.doi.org/10.1016/S0142-9612(01)00203-4

Copyright: Elsevier

http://www.elsevier.com/

Postprint available at: Linköping University Electronic Press

http://urn.kb.se/resolve?urn=urn:nbn:se:liu:diva-25793 


\title{
On the binding of complement to
}

\section{solid artificial surfaces in vitro}

\author{
Jonas Wetterö $^{\mathrm{a}}{ }^{\mathrm{b}}$, Agneta Askendal ${ }^{\mathrm{a}}$, \\ Torbjörn Bengtsson ${ }^{\mathrm{b}}$ and Pentti Tengvall ${ }^{\mathrm{a}}$
}

${ }^{a}$ Laboratory of Applied Physics, Department of Physics and Measurement

Technology, Linköping University, SE-581 83 Linköping, Sweden

${ }^{b}$ Division of Medical Microbiology, Department of Health and Environment, Faculty of Health Sciences, Linköping University, SE-581 85 Linköping, Sweden

*Corresponding author. Fax: +46 13137568

E-mail address: jonwe@ifm.liu.se

Running Title: Binding of complement to solids 


\begin{abstract}
Since the realization of a complement activation capacity by artificial surfaces upon contact with blood, a common belief has evolved that charged nucleophilic surface groups such as amine $\left(-\mathrm{NH}_{2}\right)$ and hydroxyl $(-\mathrm{OH})$ react with and eventually bind to the internal thioester in complement factor 3 (C3). A covalent ester or amide linkage is thereby supposed to form between C3b and the surface itself. In this report, we present complement surface binding data by null-ellipsometry for two nucleophilic surfaces $\left(-\mathrm{NH}_{2}\right.$ and $\left.-\mathrm{OH}\right)$, for surfaces with immunoglobulin $\mathrm{G}$ (IgG) covalently bound, and for IgG spontaneously pre-adsorbed to hydrophobic silicon. The results reveal that the plasma proteins that were deposited during complement activation became eluted by sodium dodecyl sulfate (SDS). Hence the direct covalent binding between C3 and solid nucleophilic surfaces seems to be only of moderate importance, at least during shorter serum incubations. This strongly suggests that the prevalent covalent linkage model between solid artificial surfaces and C3b is not accurate. Instead we suggest a more pronounced role for C3 associations to other adsorbed proteins and/or electrostatic and hydrophobic protein-surface interactions.
\end{abstract}

Keywords: Biomaterial; Complement activation; Protein adsorption; IgG; Hemodialysis 


\section{Introduction}

More than a century ago blood was found naturally bactericidal and the complement system was described as a heat-labile component of serum, displaying a hemolytic ability "complementary" to the already discovered heat-stable factor (antibodies). Since then the complement system has been described more in detail and designated a number of important humoral and cell-dependent biological functions like lysis, opsonization and immune complex clearance [1].

The complement cascade is an effector system consisting of more than 30 soluble and membrane-bound proteins. It can be activated through at least three different pathways. The first described "classical” activation pathway is triggered by interaction of surface-bound immunoglobulins (IgG or IgM) with complement factor 1q, C1q, and the alternative pathway is set-off by a more or less non-specific surface binding of spontaneously activated C3b [2, 3]. The recently discovered lectin pathway is initiated by carbohydrates in the cell wall of certain microorganisms $[4,5]$.

In the field of artificial biomaterials there has been an uncertainty on whether the classical or alternative activation pathway is the most relevant. Contradictory reports have emphasized the importance of both pathways, but the literature tends to favor the alternative one [6-10]. The covalent binding of complement to surfaces is indeed valid in case of immune complexes and carbohydrates as well as for a wide range of "biological" surfaces, and the biocompatibility of biomaterials designed for direct blood-contacting applications will most certainly suffer from the activation of complement, for instance illustrated by leukopenia associated with hemodialysis [11]. Also, the question whether or not implants intended for tissue integration will benefit or not from complement activation is not yet answered. A large portion of the 
biomaterial-complement research has utilized conventional radioimmunological or enzyme linked immunosorbent assays (RIA/ELISA) and/or often emphasized fluid phase products like the anaphylatoxins or soluble terminal complexes. However, also the direct surface analysis with regard to surface-bound complement proteins is of utmost importance in biomaterials research [12].

All the activation pathways form convertases that cleave native C3 into an anaphylatoxin, C3a, and the reactive and opsonizing C3b. After cleavage, the C3b molecule displays transiently a thioester bond that is susceptible to a nucleophilic attack by either surface hydroxyl or amino groups (forming ester or amide bonds) or attack by water [13-15]. Hereby C3b becomes surface-bound or remains in the fluid phase, respectively. Unlike its thioester-containing evolutionary relatives ( $\alpha_{2}$ macroglobulin and C4), C3 has been postulated to preferentially form ester rather than amide bonds [14]. The surface immobilization probably also involves a concomitant change in the backbone of the molecule [16-18]. The oxygen ester bond in the surface-immobilized C3b is physiologically susceptible to slow hydrolysis by an “auto-esterase” activity performed by the C3b molecule itself [19-21]. In vitro, stronger nucleophiles such as hydroxylamine can be used to break this bond [14, 22].

The aim of the present study was to investigate the complement retaining capacity after activation by functionalized plain solid artificial model surfaces upon short or prolonged exposure to serum. In order to accomplish this we quantified adsorbed amounts by single wavelength null-ellipsometry and identified surface localized complement proteins with polyclonal antibodies specific for C3c or C1q, respectively. 


\section{Materials and methods}

\subsection{Reagents, sera and buffers}

All reagents were of analytical grade and delivered from Sigma Chemical Co. (St. Louis, MO) unless otherwise stated. Blood was drawn from non-medicated apparently healthy volunteers and fresh normal human serum (NHS) was prepared by standard procedures and cooled on melting ice. NHS from at least two different donors were routinely pooled after preparation and stored below $-70^{\circ} \mathrm{C}$. Small vials of NHS were thawed at $37^{\circ} \mathrm{C}$ immediately before each experiment and diluted in Veronal-buffered saline (VBS; $5 \mathrm{mM}$ 5,5'-dietylbarbituric acid with it's corresponding sodium salt and $145 \mathrm{mM}$ sodium chloride, $\mathrm{pH}$ 7.4), supplemented with $0.15 \mathrm{mM} \mathrm{CaCl}_{2}$ and $0.5 \mathrm{mM} \mathrm{MgCl}_{2}\left(\mathrm{VBS}^{2+}\right)$. In control experiments, the complement activation in NHS was inhibited by the addition of $10 \mathrm{mM}$ ethylene-diaminetetraacetic acid (EDTA, Merck, Darmstadt, Germany) to the VBS (no $\mathrm{Mg}^{2+}$ or $\mathrm{Ca}^{2+}$ present). Reagents potentially sensitive to the presence of divalent cations were diluted in Phosphate-buffered saline (PBS; 10 mM sodium hydrogen phosphate, 10 mM potassium dihydrogen phosphate and $0.15 \mathrm{M}$ sodium chloride, $\mathrm{pH}$ 7.4). All buffers contained $0.25 \mathrm{mM}$ sodium azide. 


\subsection{Model surfaces}

The model surfaces were methylated silicon (hydrophobic), amine-silanized silicon or gold with adsorbed mercaptoglycerol. Some important features of the various surfaces are summarized in Table 1 and Fig. 1.

\subsubsection{Hydrophobic surfaces}

Silicon wafers (Okmetic LMTD, Esbo, Finland) were cleaved to 5 x $10 \mathrm{~mm}$ pieces in the (100) crystal direction and cleaned for 5 minutes at $80^{\circ} \mathrm{C}$ in five parts of distilled (Milli-Q) water, one part of hydrogen peroxide (30\% v/v) and one part of $\mathrm{NH}_{4} \mathrm{OH}(25 \% \mathrm{v} / \mathrm{v})$ followed by a thorough rinsing in distilled water. Thereafter, the wafers were "boiled" for 5 minutes at $80^{\circ} \mathrm{C}$ in six parts of distilled water, one part of hydrogen peroxide $(30 \% \mathrm{v} / \mathrm{v})$ and one part of hydrochloric acid $(37 \% \mathrm{v} / \mathrm{v})$, resulting in a thin hydrated surface layer of $\mathrm{SiO}_{2}[23,24]$. The water/surface static contact angle $\left(\theta_{\mathrm{w}}\right)$ was less than $10^{\circ}$ (Ramé-Hart NRL Model 100 goniometer, USA). Some of the hydrophilic wafers were washed in distilled water, technically pure ethanol and xylene (Merck, Darmstadt, Germany), and then incubated for 5 minutes at room temperature in $1 \%(\mathrm{v} / \mathrm{v})$ dichlorodimethylsilane $\left(\mathrm{Cl}_{2}\left(\mathrm{CH}_{3}\right)_{2} \mathrm{Si}\right)$ in xylene. Remaining silane was removed through sequential rinsing in ethanol, xylene and finally sonicated for one minute in a Sondrex RK100 (Bandelin Electronics, Berlin, Germany). The methylated hydrophobic $\left(\theta_{\mathrm{w}}>90^{\circ}\right)$ silicon wafers were stored in xylene and used within one week. 


\subsubsection{Amine and glutaraldehyde surfaces}

Clean and dry silicon surfaces were aminated through first 10 minutes baking of the surfaces at $60^{\circ} \mathrm{C}$ in vacuum (approximately 6 mtorr) followed by inlet of $200 \mu \mathrm{l}$ amino-propyl-triethoxysilane (APTES, Merck, Darmstadt, Germany) into the chamber and finally baked for 60 minutes at $150^{\circ} \mathrm{C}$ in vacuum. The wafers were subsequently rinsed in ethanol, xylene and sonicated for one minute. The APTES layer ellipsometric ( $n_{\text {film }}=1.5$; see below) thickness was approximately $2 \mathrm{~nm}$ and the

surfaces were stored in xylene until use. A layer of approximately $0.4 \mathrm{~nm}$ glutaraldehyde (GA) was added [25, 26] on top of the amine-functionalized surfaces by 30 minutes of incubation at room temperature in 6\% glutaraldehyde (Merck, Darmstadt, Germany) in Tris buffer ( $\mathrm{pH}$ 9) followed by triplicate rinsing in distilled water.

\subsubsection{Mercaptoglycerol surfaces}

Two hundred nanometers of gold on 9 × $9 \mathrm{~mm}$ glass slides (Biacore $\mathrm{AB}$, Uppsala, Sweden) were hydrophilized by 5 minutes of cleaning in a Model $42-220$ UVO-cleaner (Jelight Company Inc., Irvine, CA) and immediately transferred to 2 mM 3-mercapto-1,2-propanediol (mercaptoglycerol, MG, Janssen Chimica, Belgium) 
in $\mathrm{VBS}^{2+}$ at room conditions. After 30 minutes of incubation, the samples were thoroughly rinsed in distilled water and dried under nitrogen before use. The approximately $0.5 \mathrm{~nm}$ thick hydrophilic $\left(\theta_{\mathrm{w}}<10^{\circ}\right)$ glycerol layer exposes a carbon backbone and 2 hydroxyl end groups per molecule facing out from the surface and is known to spontaneously activate both the classical and alternative activation pathways $[27,28]$. The MG was not resolved from the gold when surfaces were incubated in NHS or in detergents.

\subsection{Preparation of IgG-coated surfaces}

Methylated hydrophobic surfaces were washed twice in PBS and a monolayer of normal human IgG (Gammaglobulin 165 mg/ml, Pharmacia \& UpJohn, Stockholm, Sweden) was spontaneously adsorbed during half an hour of incubation at room temperature in $1 \mathrm{mg} / \mathrm{ml}$ of IgG in PBS, followed by duplicate rinsing in PBS. Hereby a $>2 n m$ thick monolayer of IgG was formed. IgG was covalently bound to APTES + GA surfaces through a similar incubation. IgG immobilized by both procedures has proven able to activate the classical pathway of complement [29, 30] and to induce leukocyte frustrated phagocytosis in vitro [31, 32]. 


\subsection{Ellipsometry}

The flat sample surfaces were illuminated with elliptically polarized light from a HeNe $\lambda=632.8 \mathrm{~nm}$ laser at a $70^{\circ}$ angle of incidence. Two ellipsometric angles, $\Delta$ and $\psi$, were recorded at the minimum intensity of the light after reflection. By finding new angles $\psi$ and $\Delta$ after adsorption where the intensity in the analyzer is zero ("null”), the thickness of the surface film was iterated from the angle changes according to the McCrackin evaluation algorithm [33]. The film thickness was converted to amount of mass per unit area according to the algorithm by de Feijter et al [34]. The adsorption experiments were performed at $37^{\circ} \mathrm{C}$ and the samples rinsed gently four times between each type of incubation. The resulting organic films on the hydrophobic (methylated), APTES and APTES + GA surfaces were analyzed in air assuming organic film refractive index $n_{\text {film }}=1.465$ with a Rudolf Research AutoEl III (NJ, USA) and the silicon background was routinely subtracted. On Au-MG, both the incubations and film analyses were performed in situ (Fig. 1E) on samples mounted in a $37^{\circ} \mathrm{C}$ glass cuvette with assumed ambient refractive index $n_{\text {buffer }}=1.335$ $[27,35]$. The duration and concentration of the NHS (5 minutes in 10\% NHS or 45 minutes in $67 \%$, respectively) and antibody (1/50 for 30 minutes in $\mathrm{VBS}^{2+}$ ) incubations were selected on an empirical basis from previous studies [27, 30, 36]. The antibodies were IgG-fractions of polyclonal rabbit anti-human A 0062 (C3c Complement), A 0136 (C1q Complement) and A 424 (IgG, Specific for $\gamma$-Chains) 
from Dakopatts (Glostrup, Denmark) and contained protein concentrations of 10, 3.7 and $9.3 \mathrm{~g} / \mathrm{l}$ respectively.

\subsection{Stability tests on adsorbed protein layers}

In order to characterize the binding of adsorbed proteins after incubations in NHS, the samples were incubated for 30 minutes at $37^{\circ} \mathrm{C}$ in sodium dodecyl sulfate (SDS, $10.4 \mathrm{mM}$ ) or $0.1 \%(\mathrm{v} / \mathrm{v})$ Tween 20 (poly-oxyethylene sorbitan monolaurate, Kebo LabAB, Stockholm, Sweden) in PBS. SDS is capable to remove non-covalently adsorbed proteins from both hydrophobic and hydrophilic surfaces and Tween 20 is more efficient on hydrophobic than hydrophilic surfaces [37]. After elutions, the surfaces were blocked with $1 \mathrm{mg} / \mathrm{ml} \mathrm{L}$-lysine (30 minutes, $37^{\circ} \mathrm{C}$ in $\mathrm{VBS}^{2+}$ ) to inhibit a non-specific antibody binding. Possible disulfide bonds between surfaces and proteins were reduced with 5\% (v/v) 2-mercaptoethanol (Janssen Chimica, Belgium) during 30-min incubations at $37^{\circ} \mathrm{C}$ in $\mathrm{PBS}$, and ester bonds hydrolyzed during 2.5-hour incubations at $37^{\circ} \mathrm{C}$ in $1 \mathrm{M}$ hydroxylamine in a $0.2 \mathrm{M}$ Tris buffer, $\mathrm{pH}$ 9.0.

\subsection{Statistics}

Data are presented as the average values \pm standard errors of the means (SEM). The differences in NHS layer thicknesses and subsequent antibody 
depositions before and after surface treatments were analyzed using the Student's two-tailed paired $t$-test. When $p<0.05$, data were regarded as a significantly different and divided into $p<0.05, p<0.01$ or $p<0.001$ categories. All sample measurements (except for single measurements on the Au-MG surfaces) were performed at least in triplicate and $n$ always indicates the number of independent experiments, in general $\geq$ 6 (except some control experiments). 


\section{Results}

\subsection{Spontaneous complement activation by mercaptoglycerol on gold}

The Au-MG surfaces (Fig. 1A), were previously shown to spontaneously activate the complement system in vitro $[27,28]$ and to induce a strong inflammatory response in vivo [38]. Substantial amounts of NHS $(8.1 \mathrm{~nm} \pm 0.2 \mathrm{~nm})$ deposited in our experiments onto this surface after 5 minutes of exposure to 10\% NHS (Fig. 2A-B, group I). Ellipsometric detection of the concomitant binding of anti-C1q or anti-C3c revealed a strong C1q- (Fig. 2A, group I) and C3c- (Fig. 2B, group I) signal (2.6nm \pm $0.4 \mathrm{~nm}$ and $8.5 \mathrm{~nm} \pm 0.5 \mathrm{~nm}$, respectively) already after 5 minutes of incubation in NHS. When normal human IgG was used instead of the specific antibodies after the NHS-incubations, no thickening of the organic film was observed on top of the NHS film. After 45 minutes of incubation in 67\% NHS (Fig. 2C) the average NHS deposition increased to $9.8 \mathrm{~nm}( \pm 0.2 \mathrm{~nm})$ and the C1q-signal was abolished, probably due to the subsequent complement protein deposition [27]. Surprisingly, the anti-C3c binding decreased upon the prolonged NHS exposure $(6.3 \mathrm{~nm} \pm 1.0 \mathrm{~nm}$; Fig. $2 \mathrm{C}$, group I), perhaps due to inhibitors or an auto-esterase activity performed by the surfacebound C3b molecule itself. Control experiments with samples incubated for 45 minutes in EDTA-NHS indicated an approximately 6nm NHS deposition. Roughly $2 \mathrm{~nm}$ of this remained after the SDS-elution and no anti-C3c bound in to this remaining layer (not shown). 
The complement retaining capacity of the Au-MG surfaces after serum incubations was tested. SDS was able to remove almost totally the surface localized NHS proteins (Fig. 2A-B, group II) and at average only $0.7 \mathrm{~nm}( \pm 0.3 \mathrm{~nm})$ out of approximately 8nm remained on surfaces that were pre-incubated for 5 minutes in $10 \%$ NHS. The result indicates that only few direct covalent associations were formed between the surface itself and the plasma proteins (Fig. 2A-B, group II). However, lower amounts of anti-C3c or anti-C1q (29\% and 61\% of the respective original antibody signals) still bound in to the remaining protein layer, although the signals were likely overestimated after the elution step since the washing procedure may facilitate antigen-antibody contacts (a phenomena also suggested by Benesch et al. [39]). Alternatively, the blocking agent L-lysine failed to inhibit non-specific binding on the relatively clean surfaces, a theory supported by the observation that more than 1nm of normal human IgG deposited onto NHS-incubated surfaces after the SDSelutions although pre-blocked with L-lysine (not shown). After 45 minutes of incubation in $67 \%$ of NHS (Fig. 2C, group II), a thicker protein film remained after the SDS-treatment and the anti-C3c deposition decreased only by approximately one third compared to the non-eluted sample (Fig. 2C, group I). A general observation in this study was that the longer the surfaces were exposed to NHS, the more stable were the adsorbed layers against detergents and reducing agents.

The native C3 molecule consists of two subunits ( $\alpha$ and $\beta$ ) linked together by disulfide bonds [40]. We investigated the effect of disulfide bond breaking with 2mercaptoethanol for the stability of the adsorbed protein layer (Fig. 2A-C, groups IIIIV). The treatment decreased the protein film thickness with more than $40 \%$ and $36 \%$ after 5 minutes in 10\% NHS and 45 minutes in 67\% NHS, respectively. Subsequent anti-C1q and anti-C3c depositions remained high after mercaptoethanol treatments, 
$86 \%$ of the original anti-C1q signal (after 5 minutes in 10\% NHS) and 74\% / 63\% (5/ 45-min NHS incubations) of the anti-C3c deposition. When the mercaptoethanol treated protein films were subjected to SDS incubations, the layer reduced further by 43\% and 36\% (at 5- / 45-min NHS incubations, respectively). After this, only the antiC3c deposition remained significant on surfaces that were incubated for 45 minutes in NHS ( $p<0.01$; Fig. 2C, group IV). Surprisingly, the remaining layer appeared somewhat thicker than on surfaces that were treated with SDS only after the serum incubation $(p<0.01$ for 5-min incubations, not significant after 45-min incubations, compare groups II and IV). The ester bond hydrolysis with hydroxylamine on the NHS coated Au-MG samples; either pre- or post-treated with SDS, revealed results qualitatively similar to those obtained with mercaptoethanol, i.e. a low reducing capacity. The Tris buffer washing effect on NHS-coated Au-MG surfaces (2.5 hours in $37^{\circ} \mathrm{C}$ ) was of the same magnitude as the reduction performed by hydroxylamine (not shown).

In control experiments (not shown), clean APTES (amine-terminated; Fig. 1B) and clean hydrophobic (methylated) surfaces were incubated for 45 minutes in 67\% NHS. Only a moderate (approximately 3nm) NHS deposition was observed on both surfaces. Anti-C1q or anti-C3c did not deposit to NHS-coated hydrophobic surfaces, but a low anti-C3c deposition was observed on the NHS-coated APTES surfaces $(\geq$ 1.6nm). The NHS deposition on clean APTES was roughly halved by the SDS-elution and the subsequent anti-C3c deposition reduced by approximately $70 \%$. 


\subsection{IgG-triggered complement activation}

Hydroxyl-terminated surfaces are expected to activate complement via the alternative pathway. However, it was previously shown that the Au-MG surfaces activated spontaneously through the classical pathway, a phenomenon that was manifested by an early and transient detectability of IgG and C1q during NHS incubations [27]. With the above in mind we performed model experiments where complement activation was provoked with either an IgG-coating on hydrophobic silicon (non-covalent association) or with IgG covalently attached to glutaraldehyde (APTES + GA surfaces).

\subsubsection{Non-covalent IgG-coating}

IgG-coated hydrophobic surfaces (Fig. 1C) deposited 2.0nm $\pm 0.3 \mathrm{~nm}$ of plasma proteins after 5 minutes incubation in 10\% NHS (Fig. 3A-B, group I). Both C1q and C3c were clearly detectable with respective antibody $(1.6 \mathrm{~nm} \pm 0.3 \mathrm{~nm} ; p<$ 0.01 and $4.3 \mathrm{~nm} \pm 0.4 \mathrm{~nm} ; p<0.001$ ). After 45 minutes of incubation in $67 \%$ NHS (Fig. 3C, group I), the additional protein deposition was massive $(10.3 \mathrm{~nm} \pm 0.3 \mathrm{~nm}, p$ 
$<0.001$ ) and incubation in anti-C3c resulted in a large additional mass deposition $(10.1 \mathrm{~nm} \pm 0.5 \mathrm{~nm} ; p<0.001)$.

The subsequent SDS incubations reduced the NHS layers to below the IgGmonolayer levels after both the 5-min $(1.4 \mathrm{~nm} \pm 0.1 \mathrm{~nm} ; p<0.001)$ and 45 -min NHS incubations ( $2.3 \mathrm{~nm} \pm 0.1 \mathrm{~nm} ; p<0.001)$, but failed to completely remove the proteins (Fig. 3A-C, group II). The relative anti-C1q deposition to the 5 minutes in NHS surfaces was reduced by $80 \%$ (Fig. 3A, group II) and only $9 \%$ (at 5-min, Fig. 3B, group II) or 19\% (at 45-min, Fig. 3C, group II) of the anti-C3c-binding remained after the SDS elutions. Mercaptoethanol removed $44 \%$ of the 5 -min and $57 \%$ of the $45-\mathrm{min}$ NHS depositions, respectively. Subsequently, no anti-C1q bound to the surfaces. The remaining anti-C3c deposition, however, was 52\% (5 minutes in NHS) and 61\% (45 minutes in NHS) compared to depositions without SDS treatment (group I). Preincubation of the NHS-coated samples in mercaptoethanol before SDS and antibody incubations did not facilitate SDS elution (rather the opposite) and the anti-C1q or anti-C3c depositions remained similar to those obtained after SDS treatment only.

Since SDS could not completely remove the deposited NHS proteins, another detergent known to disrupt the lateral stability of adsorbed protein layers, Tween 20, was introduced (Fig. 3D, groups II and IV). This resulted in only a low reduction of the 45-min in NHS layer, and the washing capacity was modest. The anti-C3c deposition remained high after the washings and Tween 20 could neither affect the NHS layer thickness nor the anti-C3c signal following the mercaptoethanol treatment. In order to test if the failure of SDS to totally clean the surfaces was due to "residence time effects” of adsorbed proteins, we tested the elution capacity of both detergents on IgG monolayers (Fig. 3E, groups I and II). Apparently, SDS was able to remove the 
major part (but not all) of the pre-adsorbed IgG-monolayer even after prolonged residence time in buffer (no significant difference between the 1-minute and 45-min samples). When the IgG-coated samples were exposed to NHS, a decrease in the elutability by SDS was observed and the remaining layer increased from $1.2 \mathrm{~nm} \pm$ $0.1 \mathrm{~nm}$ to $2.6 \mathrm{~nm} \pm 0.2 \mathrm{~nm}$ (Fig. 3E, groups III and IV). The already observed modest washing effects of Tween 20 declined further with increased residence time on both IgG only and on IgG surfaces after incubation in NHS.

\subsubsection{Covalently bound $\operatorname{Ig} G$}

Surfaces with covalently bound IgG (Fig. 1D) were incubated for 5 or 45 minutes in NHS, and deposited $2.3 \mathrm{~nm} \pm 0.2 \mathrm{~nm}$ and $10.0 \mathrm{~nm} \pm 0.3 \mathrm{~nm}$ (respectively) of proteins on top of the IgG layer (Fig. 4A-C, group I). Upon a subsequent incubation in anti-C1q the thickness increased by $2.1 \mathrm{~nm} \pm$ 0.2nm (5-min incubation; Fig. 4A, group I). The anti-C3c binding was significantly larger, $4.9 \mathrm{~nm} \pm 0.2 \mathrm{~nm}$ after the 5 -min incubation (Fig. 4B, group I) and $8.4 \mathrm{~nm} \pm 0.5 \mathrm{~nm}$ after the $45-\mathrm{min}$ incubation (Fig. 4C, group I).

SDS reversed the 5-min NHS deposition almost back to the IgG-background level although the washing effect was smaller for the 45-min NHS layer $(22 \%, p<$ 0.001). The subsequent anti-C1q-deposition was significant $(p<0.05)$ but low (a couple of Ångströms, Fig. 4A, group II). The anti-C3c signal became lower after the SDS-elution, but remained at a fairly high level, $1.0 \mathrm{~nm} \pm 0.1 \mathrm{~nm}$ after 5 minutes of 
NHS incubation (Fig. 4B, group II) and $3.9 \mathrm{~nm} \pm 0.3 \mathrm{~nm}$ after the 45 -min NHS incubation (Fig. 4C, group II). Treatment with mercaptoethanol after the NHS incubation gave results similar to those for the above-described IgG-coated hydrophobic surface. Interestingly, the combined washing effect of mercaptoethanol followed by a SDS treatment completely abolished the anti-C3c binding. Incubation for 30 minutes at $37^{\circ} \mathrm{C}$ in $\mathrm{VBS}^{2+}$ showed only a small (approximately 10\%) rinsing effect after 45 minutes of NHS deposition and the subsequent anti-C3c binding was not reduced (not shown).

The relatively powerful reducing agent hydroxylamine was capable to remove up to $56 \%$ of the NHS layer that was formed after 45 minutes of incubation in $67 \%$ NHS $(p<0.001$ ) and decreased the subsequent anti-C3c-signal by 19\% (Fig. 4D, group III). In comparison, upon 2.5 hours of incubation in the corresponding Tris buffer 39\% of the NHS was removed ( $p<0.001$ ), and the anti-C3c deposition was almost unaffected (not shown). The combination of hydrolysis by hydroxylamine and SDS elution was very effective but did not reset the complement/NHS protein layer down to IgG-levels. The remaining layer thickness was $3.1 \mathrm{~nm} \pm 0.3 \mathrm{~nm}$, not significantly different from the IgG layer only, and some anti-C3c could be deposited onto this remaining layer (19\% of the reference anti-C3c deposition, Fig. 4D, group I). 


\section{Discussion}

Studies that are made to elucidate the mechanisms behind frustrated leukocyte phagocytosis as a consequence of complement activation at the blood - biomaterial interface are complex. The reason for the violent inflammatory cell reaction is probably multi-factorial and involves several humoral and cellular systems. For instance, C1q, C3-fragments and IgG act independently with leukocyte cell surface receptors, and they dramatically increase the adhesion and respiratory burst events in synergy [41, 42]. Therefore we cannot determine the properties of the surface stimuli solely by concluding that frustrated phagocytosis occurs at an interface. We demonstrate in the present, and in earlier studies that the deposition of both anti-C1q and anti-C3c was extensive and significant when Au-MG surfaces were exposed to NHS. Qualitatively similar results were obtained when IgG was pre-adsorbed or covalently bound to surfaces. The specific polyclonal antibodies that were used are large molecules $(150 \mathrm{kDa})$ and these are unlikely to penetrate through the supposedly dense layer of packed plasma proteins, indicating that complement proteins were immunologically accessible on top of the adsorbed protein layers. This does not, however, give us information on whether the detected C1q and C3 molecules were firmly bound or in direct association with the actual surface or not. Therefore, incubations in detergents or reducing solutions provided in this case valuable information about the characteristics of protein binding after complement was activated on the present known activator surfaces. 
It is well known that SDS denatures soluble proteins, and the surface binding of C3b involves a denaturation similar to that accompanying an SDS treatment [16, 18]. Traditionally, SDS is used to remove non-covalently bound proteins [14]. Cornelius and Brash [43] demonstrated that C3 was present in SDS eludates after plasma incubations of a number of hemodialysis membranes. In accordance with this, we show in the present study that SDS has a dramatic washing effect on different complement activator surfaces. Also, SDS-elutions often substantially decreased the subsequent $\mathrm{C} 3 \mathrm{c}$ and $\mathrm{C} 1 \mathrm{q}$ antibody binding into the remaining protein layer. Upon SDS-treatment of the NHS exposed Au-MG surface, the protein layer was almost completely removed, and a similar low NHS layer thickness was obtained on noncharged hydrophobic (methylated) surfaces. We therefore find it unlikely that the present complement activator surfaces had a large number of direct covalent bonds to complement proteins. In addition, in this study, the ester linkage disruption by hydroxylamine as well as disulfide breaking by mercaptoethanol was only of partial importance.

It should be emphasized that the chemical surface functionality has a great impact on its complement activation capacity [44]. The role of a direct amide or ester linkage between an amine- or hydroxyl-terminated surface and C3b seems in light of the present results to be overestimated in the literature. Cheung et al. [8, 45] and Gachon et al. [44] showed that the complement activation potential of hemodialysis membranes is not directly correlated to the number of potential surface activation sites for C3b. Hence, and for other reasons reviewed by Janatova et al. [46], the covalent C3 binding model, that may be relevant to biological surfaces, cannot be directly transferred to artificial surfaces. 
The C3-opsonization of the present model surfaces, and most likely also of other blood contacting artificial surfaces, probably occurs through multiple interactions between C3 and other rapidly adsorbed proteins. The molecular weight of C3 is $185 \mathrm{kDa}$ [40] and therefore it diffuses therefore relatively slowly compared to e.g. albumin, IgG, etc. to surfaces. In other studies, strong covalent associations between albumin and C3-fragments have been reported [47, 48]. Furthermore, IgG and $\mathrm{C} 1 \mathrm{q}$ are transiently detectable at the Au-MG surfaces after contact with NHS [27], and IgG enhances the alternative pathway activation via the classical pathway [3]. Surprisingly, the SDS elutability of NHS was dramatically lower on the surface with covalently immobilized IgG. This surface probably behaves similar to immune aggregates that bind covalently to C3b, probably via an amide bond [49]. The amide bond is not sensitive to nucleophilic attack [20], this may explain why the anti-C3c binding was not totally abolished on surfaces with covalently attached IgG after incubations in hydroxylamine and SDS. In contrast, IgG has been shown to possess a C3 binding site between Val-134 and Lys-156 on the CH1 domain of IgG 1 , which probably forms an ester by reacting with the C3 thioester [50]. However, this covalent IgG-C3b ester association has been demonstrated sensitive to hydroxylamine, thus suggesting further investigations. An alternative and less likely explanation for the high deposition of anti-C3c on NHS layers could be that fluid phase C3c (that lacks the thioester) is present at the surfaces due to a passive protein adsorption $[8,45]$. Thus, our suggestion is that leukocytes probably encounter rather an opsonized protein layer than an opsonized surface during the frustrated phagocytosis process upon contact with a flat solid artificial surface.

It should also be emphasized that C3b likely binds to glycosylated proteins [51], and the length of polysaccharide chains on biological particles affects the C3b 
affinity for the soluble complement inhibiting factor $\mathrm{H}[52,53]$. In an ellipsometric study that was recently performed in our laboratory with $\mathrm{HS}\left(\mathrm{CH}_{2}\right)_{15} \mathrm{CONH}\left(\left(\mathrm{CH}_{2}\right)_{2} \mathrm{O}\right)_{6} \mathrm{H}$ self assembled on gold, only $15 \%$ of the NHS deposition after 30 minutes of incubation in 67\% NHS could be removed by SDS [39]. This indicates that the surface - protein molecule penetration depth is of importance for the complement retaining capacity of an artificial surface.

\section{Conclusions}

We suggest that complement upon activation at solid artificial surfaces primarily associates to other adsorbed proteins. The extent of covalent C3 surface binding is minor and the deposition of C3b most likely occurs via electrostatic and hydrophobic interactions. The elutability of adsorbed NHS proteins decreases with time.

\section{Acknowledgements}

We acknowledge the Swedish Biomaterials Consortium (Swedish National Foundation for Strategic Research, SSF), the Swedish Medical Research Council (grant number 71X-12668) and the local Linköping Lion Foundation (Forskningsfond mot folksjukdomar) for their financial support. 


\section{References}

1 Cooper NR. Biology of the complement system. In: Gallin, JI and Snyderman, R, eds. Inflammation: Basic Principles and Clinical Correlates. Philadelphia: Lippincott Williams \& Wilkins, 1999. p. 281-315.

2 Loos M, Trinder PKE, Kaul M. Factors of the classical pathway. In: Rother, K, Till, GO and Hänsch, GM, eds. The complement system. Heidelberg: Springer Verlag Berlin, 1998. p. 1-23.

3 Pangburn MK. Alternative pathway: Activation and regulation. In: Rother, K, Till, GO and Hänsch, GM, eds. The complement system. Heidelberg: Springer Verlag Berlin, 1998. p. 93-115.

4 Ikeda K, Sannoh T, Kawasaki N, Kawasaki T, Yamashina I. Serum lectin with known structure activates complement through the classical pathway. J Biol Chem 1987;262:7451-4.

5 Reid KBM. Lectin Pathway of non-self recognition. In: Rother, K, Till, GO and Hänsch, GM, eds. The complement system. Heidelberg: Springer Verlag Berlin, 1998. p. 86-92.

6 Chenoweth DE. Complement activation in extracorporeal circuits. Ann NY Acad Sci 1987;516:306-13.

7 Kazatchkine MD, Carreno MP. Activation of the complement system at the interface between blood and artificial surfaces. Biomaterials 1988;9:30-5. 
8 Cheung AK, Parker CJ, Wilcox L, Janatova J. Activation of the alternative pathway of complement by cellulosic hemodialysis membranes. Kidney Int 1989;36:257-65.

9 Lhotta K, Wurzner R, Kronenberg F, Oppermann M, Konig P. Rapid activation of the complement system by cuprophane depends on complement component C4. Kidney Int 1998;53:1044-51.

10 Hirata I, Morimoto Y, Murakami Y, Iwata H, Kitano E, Kitamura H, Ikada Y. Study of complement activation on well-defined surfaces using surface plasmon resonance. Colloids Surf B 2000;18:285-292.

11 Chenoweth DE. Complement activation during hemodialysis: clinical observations, proposed mechanisms, and theoretical implications. Artif Organs 1984;8:281-90.

12 Gemmell CH. A flow cytometric immunoassay to quantify adsorption of complement activation products (iC3b, C3d, SC5b-9) on artificial surfaces. J Biomed Mater Res 1997;37:474-80.

13 Law SK, Levine RP. Interaction between the third complement protein and cell surface macromolecules. Proc Nat Acad Sci 1977;74:2701-5.

14 Law SK, Lichtenberg NA, Levine RP. Evidence for an ester linkage between the labile binding site of $\mathrm{C} 3 \mathrm{~b}$ and receptive surfaces. $\mathrm{J}$ Immunol 1979;123:1388-94.

15 Law SK, Dodds AW. The internal thioester and the covalent binding properties of the complement proteins C3 and C4. Protein Sci 1997;6:263-74. 
16 Nilsson B, Nilsson UR. An assessment of the extent of antigenic analogy between physiologically bound C3 and C3 denatured by sodium dodecyl sulphate. Scand J Immunol 1985;22:703-10.

17 Nilsson B, Nilsson UR. SDS denaturation of complement factor C3 as a model for allosteric modifications occurring during C3b binding: demonstration of a profound conformational change by means of circular dichroism and quantitative immunoprecipitation. Immunol Lett 1986;13:11-4.

18 Nilsson B, Ekdahl KN, Svensson KE, Bjelle A, Nilsson UR. Distinctive expression of neoantigenic C3(D) epitopes on bound C3 following activation and binding to different target surfaces in normal and pathological human sera. Mol Immunol 1989;26:383-90.

19 Venkatesh YP, Minich TM, Levine RP. Hydrolysis of the covalent bond of C3b-/C3-small-molecule complexes under physiological conditions. Ann NY Acad Sci 1983;421:313-5.

20 Venkatesh YP, Minich TM, Law SK, Levine RP. Natural release of covalently bound C3b from cell surfaces and the study of this phenomenon in the fluidphase system. J Immunol 1984;132:1435-9.

21 Venkatesh YP, Levine RP. The esterase-like activity of covalently bound human third complement protein. Mol Immunol 1988;25:821-8.

22 Sim RB, Twose TM, Paterson DS, Sim E. The covalent-binding reaction of complement component C3. Biochem J 1981;193:115-27. 
23 Kern W, Puotinen DA. Cleaning solutions based on hydrogen peroxide for use in silicon semiconductor technology. RCA Rev 1970;187-206.

24 Peters DA, Deckert CA. Removal of photoresist film residues from wafer surfaces. J Elechtrochem Soc 1979;883-886.

25 Hermansson GT, Mallia AK, K. SP. Immobilized affinity ligand techniques. San Diego, CA: Academic Press, Inc., 1992.

26 Weetall HH. Preparation of immobilized proteins covalently coupled through silane coupling agents to inorganic supports. Appl Biochem Biotechnol 1993;41:157-88.

27 Tengvall P, Askendal A, Lundstrom I. Complement activation by 3-mercapto1,2-propanediol immobilized on gold surfaces. Biomaterials 1996;17:1001-7.

28 Liu L, Elwing H. Complement activation on thiol-modified gold surfaces. J Biomed Mater Res 1996;30:535-41.

29 Liu L, Elwing H. Complement activation on solid surfaces as determined by C3 deposition and hemolytic consumption. J Biomed Mater Res 1994;28:76773.

30 Tengvall P, Askendal A, Lundstrom I. Complement activation by IgG immobilized on methylated silicon. J Biomed Mater Res 1996;31:305-12.

31 Liu L, Elwing H, Karlsson A, Nimeri G, Dahlgren C. Surface-related triggering of the neutrophil respiratory burst. Characterization of the response induced by IgG adsorbed to hydrophilic and hydrophobic glass surfaces. Clin Exp Immunol 1997;109:204-10. 
32 Wetterö J, Bengtsson $\mathrm{T}$, Tengvall $\mathrm{P}$. Complement activation on immunoglobulin G-coated hydrophobic surfaces enhances the release of oxygen radicals from neutrophils through an actin-dependent mechanism. J Biomed Mater Res 2000;51:742-751.

33 McCrackin FL. (1969) in NBS Technical Note 479, Washington DC.

34 de Feijter JA, Benjamins J, Veer FA. Ellipsometry as a tool to study the adsorption of synthetic and biopolymers at the air-water interface. Biopolymers 1978;17:1759-73.

35 Walivaara B, Askendal A, Lundstrom I, Tengvall P. Blood protein interactions with titanium surfaces. J Biomaterials Sci, Polymer Ed 1996;8:41-8.

36 Tengvall P, Askendal A, Lundstrom I. Temporal studies on the deposition of complement on human colostrum IgA and serum IgG immobilized on methylated silicon. J Biomed Mater Res 1997;35:81-92.

37 Elwing H, Welin S, Askendal A, Nilsson U, Lundström I. A wettability gradient method for studies of macromolecular interactions at the liquid/solid interface. J Colloid Interface Sci 1987;119:203-210.

38 Tang L, Liu L, Elwing HB. Complement activation and inflammation triggered by model biomaterial surfaces. J Biomed Mater Res 1998;41:333-40.

39 Benesch J, Svedhem S, Svensson SCT, Valiokas R, Liedberg B, Tengvall P. Protein adsorption on oligo(Ethylene Glycol) self assembled monolayers: Experiments with fibrinogen, heparinised plasma and serum. J Biomaterials Sci, Polymer Ed 2001;In Press. 
40 Nilsson B, Nilsson Ekdahl K. Components of the alternative pathway. In: Rother, K, Till, GO and Hänsch, GM, eds. The complement system. Heidelberg: Springer Verlag Berlin, 1998. p. 23-49.

41 Zhou MJ, Brown EJ. CR3 (Mac-1, alpha M beta 2, CD11b/CD18) and Fc gamma RIII cooperate in generation of a neutrophil respiratory burst: requirement for Fc gamma RIII and tyrosine phosphorylation. J Cell Biol 1994;125:1407-16.

42 Goodman EB, Anderson DC, Tenner AJ. C1q triggers neutrophil superoxide production by a unique CD18-dependent mechanism. J Leukocyte Biol 1995;58:168-76.

43 Cornelius RM, Brash JL. Identification of proteins absorbed to hemodialyser membranes from heparinized plasma. J Biomaterials Sci, Polymer Ed 1993;4:291-304.

44 Francoise Gachon AM, Mallet J, Tridon A, Deteix P. Analysis of proteins eluted from hemodialysis membranes. J Biomaterials Sci, Polymer Ed $1991 ; 2: 263-76$

45 Cheung AK, Parker CJ, Janatova J. Analysis of the complement C3 fragments associated with hemodialysis membranes. Kidney Int 1989;35:576-88.

46 Janatova J, Cheung AK, Parker CJ. Biomedical polymers differ in their capacity to activate complement. Complement Inflamm 1991;8:61-9. 
47 Stossel TP, Field RJ, Gitlin JD, Alper CA, Rosen FS. The opsonic fragment of the third component of human complement (C3). J Exp Med 1975;141:132947.

48 Johnson U, Holmstrom E. C3 fragmentation in human serum: formation of a mixed disulphide between C3d and albumin. Acta Pathol Microbiol Immunol Scand 1982;90:321-6.

49 Gadd KJ, Reid KB. The binding of complement component C3 to antibodyantigen aggregates after activation of the alternative pathway in human serum. Biochem J 1981;195:471-80.

50 Sahu A, Pangburn MK. Covalent attachment of human complement C3 to IgG. Identification of the amino acid residue involved in ester linkage formation. J Biol Chem 1994;269:28997-9002.

51 Zhang W, Lachmann PJ. Glycosylation of IgA is required for optimal activation of the alternative complement pathway by immune complexes. Immunology 1994;81:137-41.

52 Pangburn MK. Analysis of recognition in the alternative pathway of complement. Effect of polysaccharide size. J Immunol 1989;142:2766-70.

53 Pangburn MK. Analysis of the mechanism of recognition in the complement alternative pathway using C3b-bound low molecular weight polysaccharides. J Immunol 1989;142:2759-65. 


\section{LEGENDS TO TABLE AND FIGURES}

Table 1. Summary of some characteristics of the model surfaces. See also Materials and methods.

Fig. 1. Schematic illustrations of the four complement activating surfaces (A-D) and the in situ ellipsometric measurement set-up (E, modified from [35]). In (B), the silane also polymerizes laterally [26]. For details, see Materials and methods (abbreviations: IgG = immunoglobulin G, GA = glutaraldehyde, $\mathrm{E}=$ electric field, $\mathrm{s}=$ perpendicular, $\mathrm{p}$ = parallel, $\mathrm{i}$ = incident light, $\mathrm{r}$ = reflected light).

Fig. 2. Spontaneous complement activation induced by the hydroxyl-containing mercaptoglycerol on gold (Au-MG). The Au-MG-surfaces were mounted in a heatcontrolled $\left(37^{\circ} \mathrm{C}\right)$ measurement cell and the protein adsorption from normal human serum (NHS) was measured in situ by null ellipsometry (Fig. 1E). The samples were rinsed gently four times between each treatment and all measurements were performed in veronal buffered saline supplemented with $\mathrm{Mg}^{2+}$ and $\mathrm{Ca}^{2+}\left(\mathrm{VBS}^{2+}\right)$. Antibodies were added at $1 / 50$ dilutions in $\mathrm{VBS}^{2+}$ for 30 minutes. The surfaces were blocked for non-specific binding with $1 \mathrm{mg} / \mathrm{ml}$ L-lysine (15 minutes, $\mathrm{VBS}^{2+}$ ) in (A) and (B). The bars indicate standard errors of the means (SEM, $n=6$ ).

(A) 5 minutes in 10\% NHS. Subsequent binding of anti-C1q before and after sodium dodecyl sulfate elutions (SDS, $10.4 \mathrm{mM}$ in phosphate buffered saline, PBS) and before and after reduction with 5\% (v/v) mercaptoethanol (in $\mathrm{VBS}^{2+}$ ).

(B) As (A) but shows the binding of anti-C3c. 
(C) 45 minutes incubation in 67\% NHS. Subsequent binding of anti-C3c before and after SDS elutions and before and after reduction with mercaptoethanol.

Fig. 3. Complement activation triggered by IgG-precoated hydrophobic silicon. The protein deposition from normal human serum (NHS) onto a spontaneously adsorbed monolayer of immunoglobulin G (IgG) was measured with null ellipsometry in air. All incubation steps were performed sequentially with four rinsing steps in between, at $37^{\circ} \mathrm{C}$. Triplicate film measurements were performed at different spots.

(A) 5 minutes in 10\% NHS. Subsequent binding of anti-C1q before and after sodium dodecyl sulfate elutions (SDS, $10.4 \mathrm{mM}$ in phosphate buffered saline, PBS, followed by blocking with $1 \mathrm{mg} / \mathrm{ml}$ L-lysine for 15 minutes in veronal buffered saline, $\mathrm{VBS}^{2+}$ ) and before and after reduction with 5\% (v/v) mercaptoethanol (in $\left.\operatorname{VBS}^{2+}\right) .(n=6)$.

(B) As (A) but shows the binding of anti-C3c. $(n=6)$.

(C) 45 minutes incubation in 67\% NHS. Subsequent binding of anti-C3c before and after SDS elutions and before and after reduction with mercaptoethanol. $(n=9)$.

(D) As (C) but with SDS exchanged for $0.1 \%$ (v/v) Tween 20 (poly-oxyethylene sorbitan monolaurate). $(n=6)$.

(E) Elutability of NHS on IgG layers after 1- or 45-minute incubations. $(n=6)$.

Fig. 4. Complement activation by covalently immobilized IgG on amino-propyltriethoxysilane (APTES) + diglutaraldehyde (GA) on silicon. The samples were exposed to normal human serum (NHS) diluted in veronal buffered saline supplemented with $\mathrm{Mg}^{2+}$ and $\mathrm{Ca}^{2+}\left(\mathrm{VBS}^{2+}\right)$. The protein depositions were studied by 
null-ellipsometry in air. The samples were kept at $37^{\circ} \mathrm{C}$ throughout the various incubations and gently rinsed $(\mathrm{x} 4)$ in $\mathrm{VBS}^{2+}$ before analysis.

(A) 5 minutes in 10\% NHS. Subsequent binding of anti-C1q before and after sodium dodecyl sulfate elutions (SDS, $10.4 \mathrm{mM}$ in phosphate buffered saline, PBS, followed by blocking with $1 \mathrm{mg} / \mathrm{ml}$ L-lysine for 15 minutes in $\mathrm{VBS}^{2+}$ ) and before and after reduction with 5\% mercaptoethanol (in $\left.\mathrm{VBS}^{2+}\right) .(n=10)$.

(B) As (A) but shows the binding of anti-C3c. $(n=10)$.

(C) 45 minutes incubation in 67\% NHS. Subsequent binding of anti-C3c before and after SDS elutions and before and after reduction with mercaptoethanol. $(n=6)$.

(D) Effect of reduction with $1 \mathrm{M}$ hydroxylamine (2.5 hour in $0.2 \mathrm{M}$ Tris buffer, $\mathrm{pH}$ 9.0) on the NHS layer after 45 minutes of incubation in 67\% NHS. $(n=7)$. 
TABLE 1

\begin{tabular}{l|cccc}
\hline \multicolumn{1}{c|}{ Model coating } & Bulk substrate & $\begin{array}{c}\text { Medium for } \\
\text { optical } \\
\text { analysis }\end{array}$ & $\begin{array}{c}\text { Surface water } \\
\text { contact angle } \\
\left(\theta_{\mathrm{w}}\right)\end{array}$ & $\begin{array}{c}\text { Terminal } \\
\text { functionality }\end{array}$ \\
\hline Hydrophobic & $\mathrm{Si}$ & Air & $>90^{\circ}$ & $-\mathrm{CH}_{3}$ \\
$\begin{array}{l}\text { Amino-propyl-triethoxysilane } \\
\text { (APTES) }\end{array}$ & $\mathrm{Si}$ & Air & $<10^{\circ}$ & $-\mathrm{NH}_{2}$ \\
$\begin{array}{l}\text { Amino-propyl-triethoxysilane + } \\
\text { diglutaraldehyde (APTES + GA) }\end{array}$ & $\mathrm{Si}$ & Air & $40^{\circ}<\theta_{\mathrm{w}} \leq 60^{\circ}$ & $-\mathrm{CHO}$ \\
\begin{tabular}{l} 
Mercaptoglycerol (Au-MG) \\
\hline
\end{tabular} & Au (on glass) & $\mathrm{VBS}^{2+}$ & $<10^{\circ}$ & $-\mathrm{OH}$ \\
\hline
\end{tabular}


“Binding of complement to solids” - Wetterö et al.

\section{FIGURE 1}

Not available in this open access version. 
“Binding of complement to solids” - Wetterö et al.

\section{FIGURE 2}




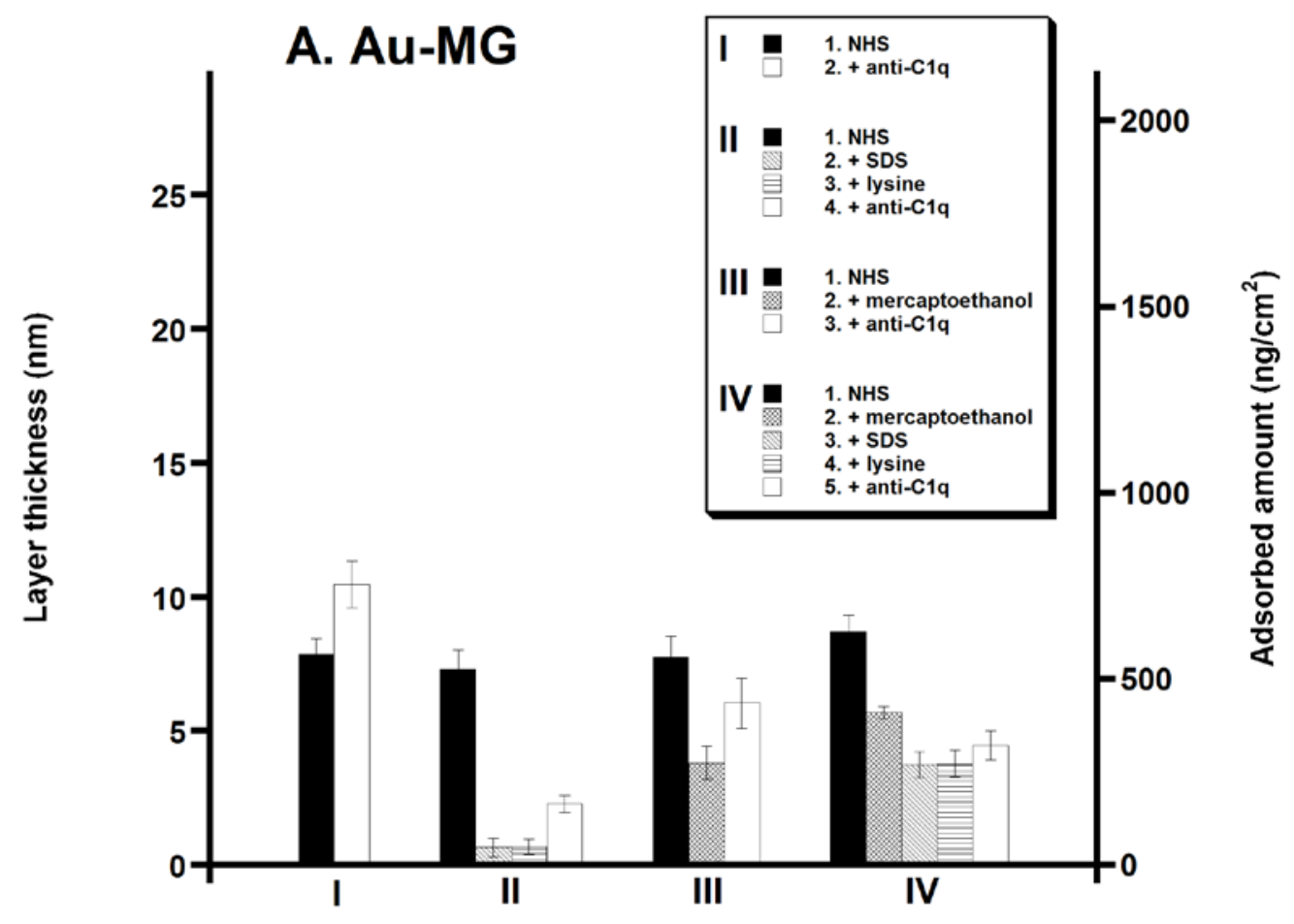




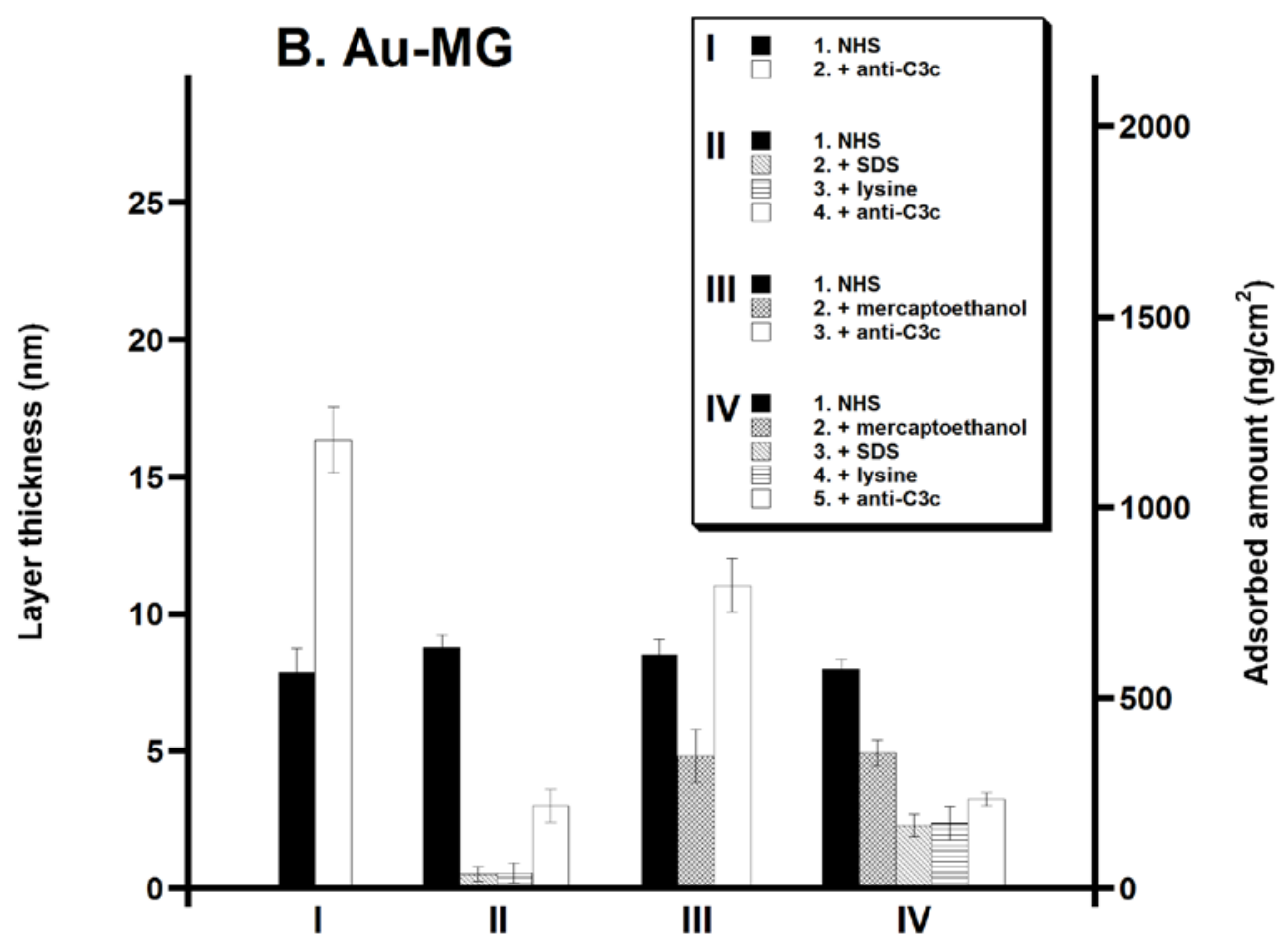




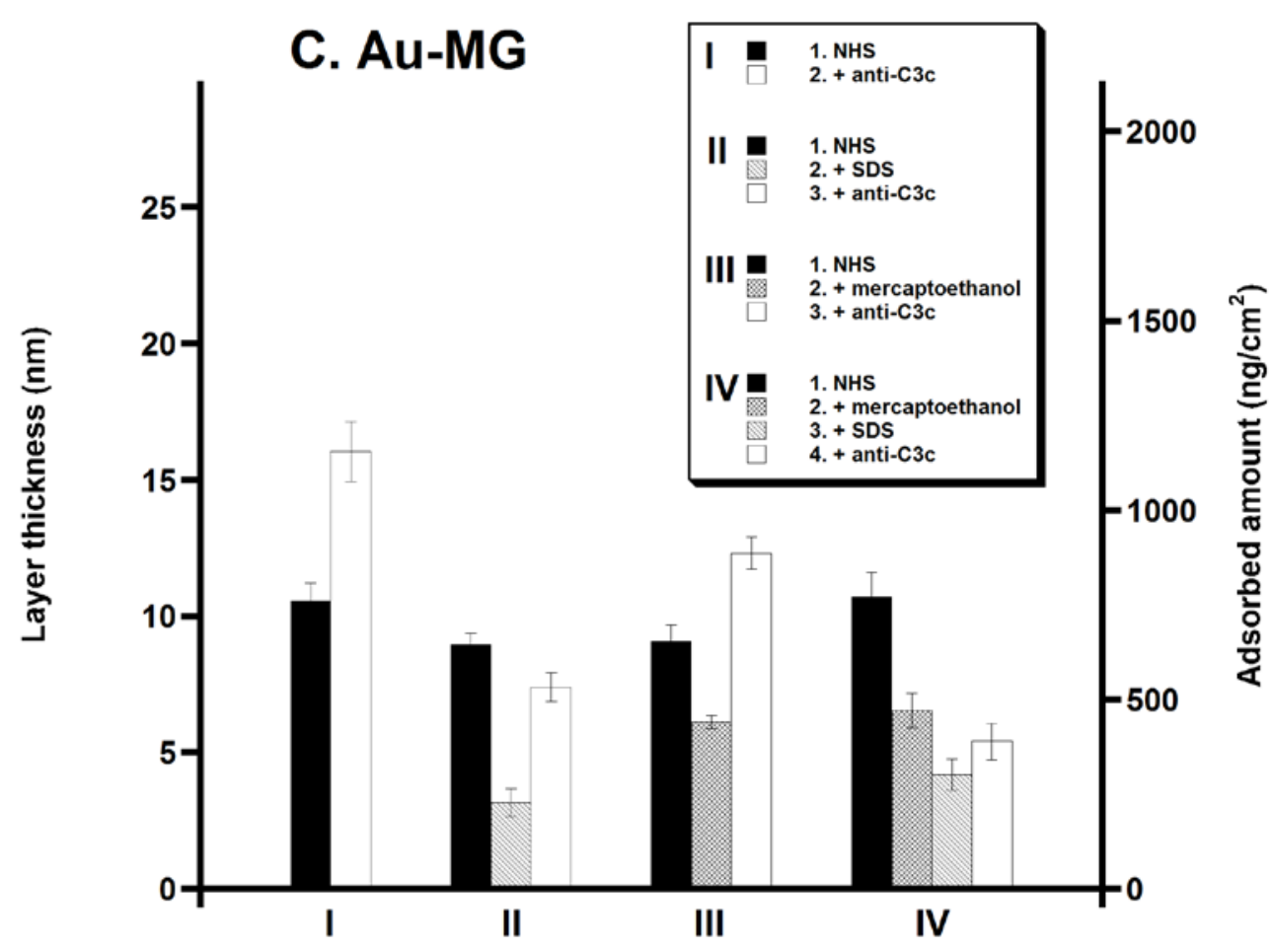


“Binding of complement to solids”-Wetterö et al.

\section{FIGURE 3}




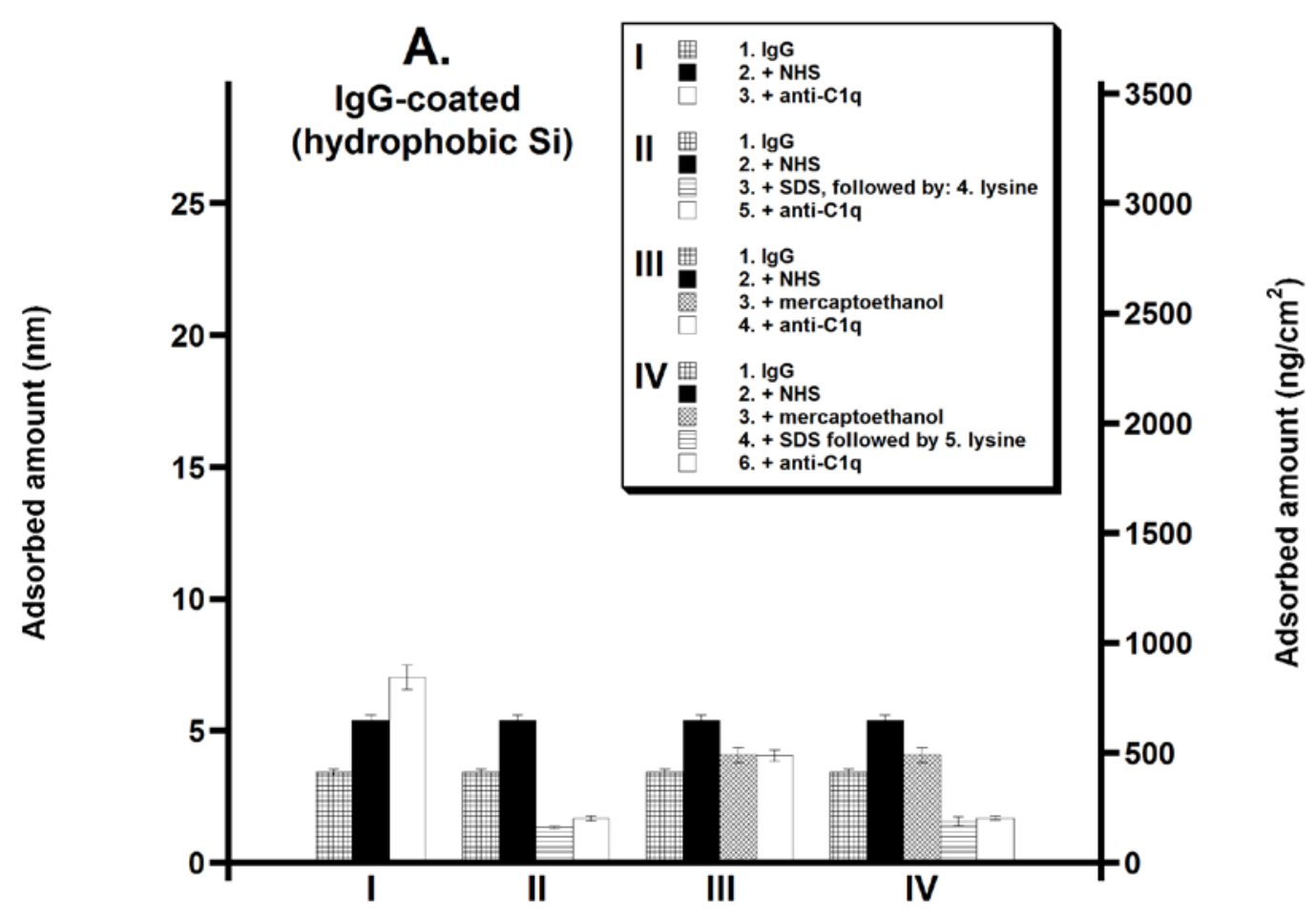




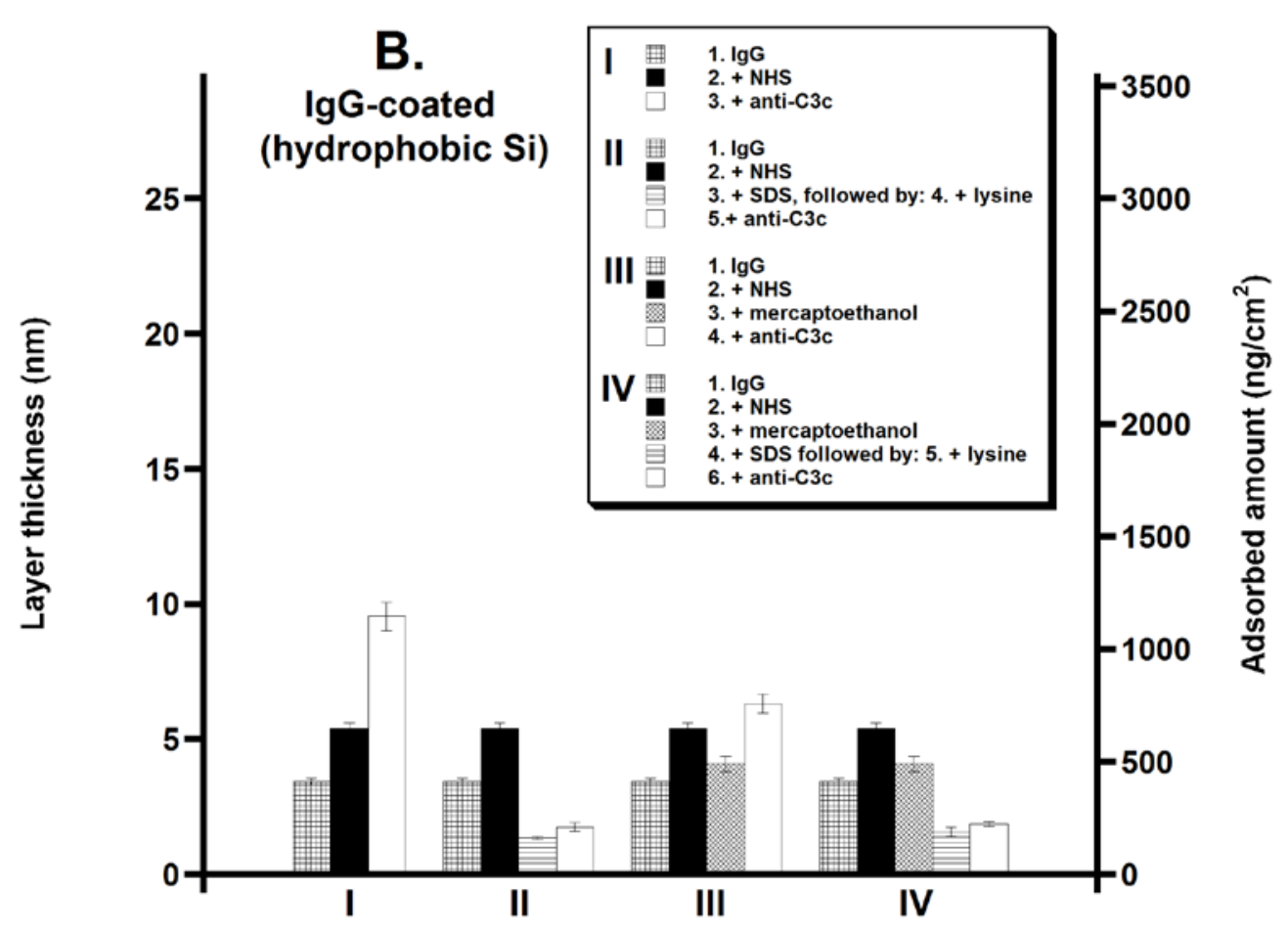




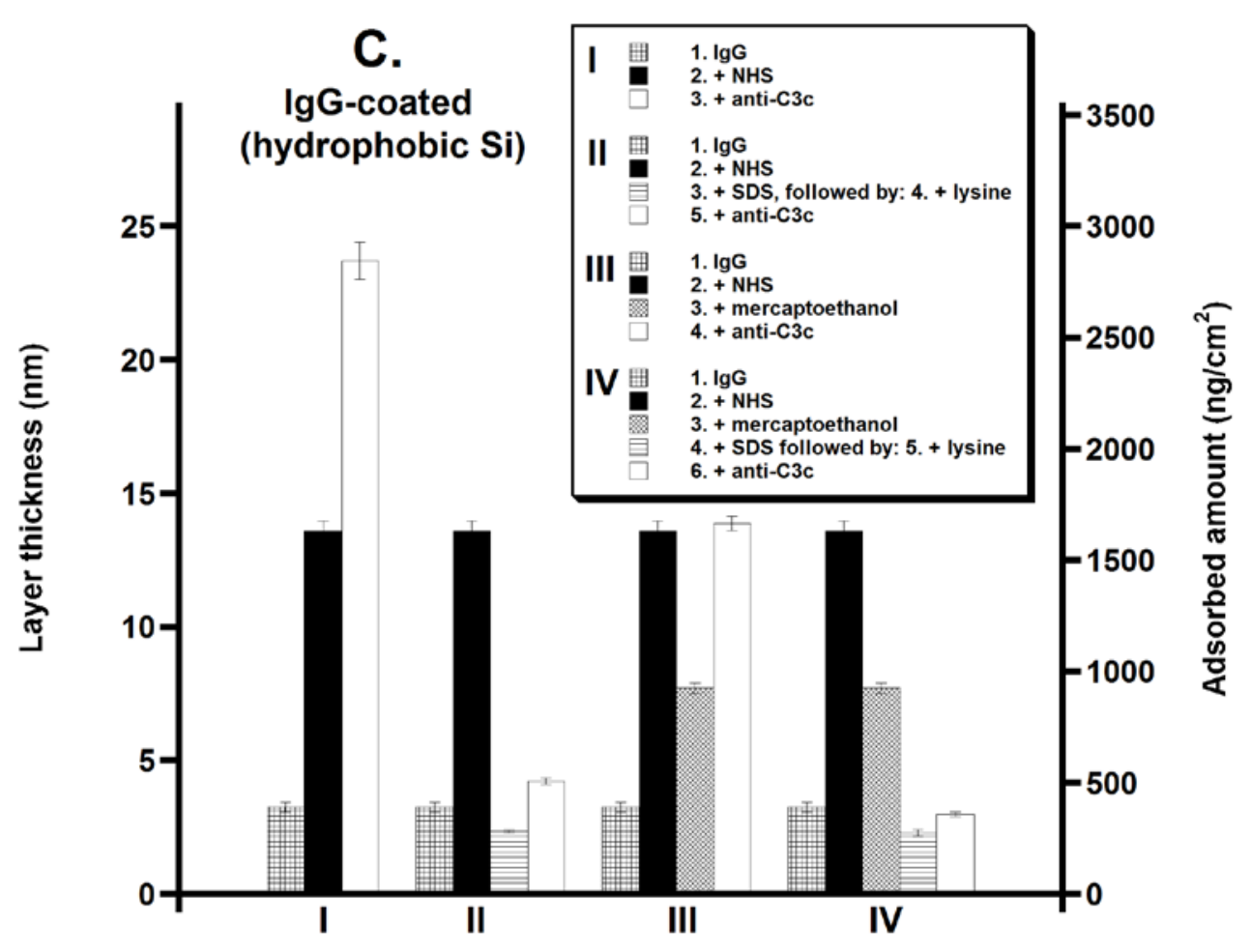




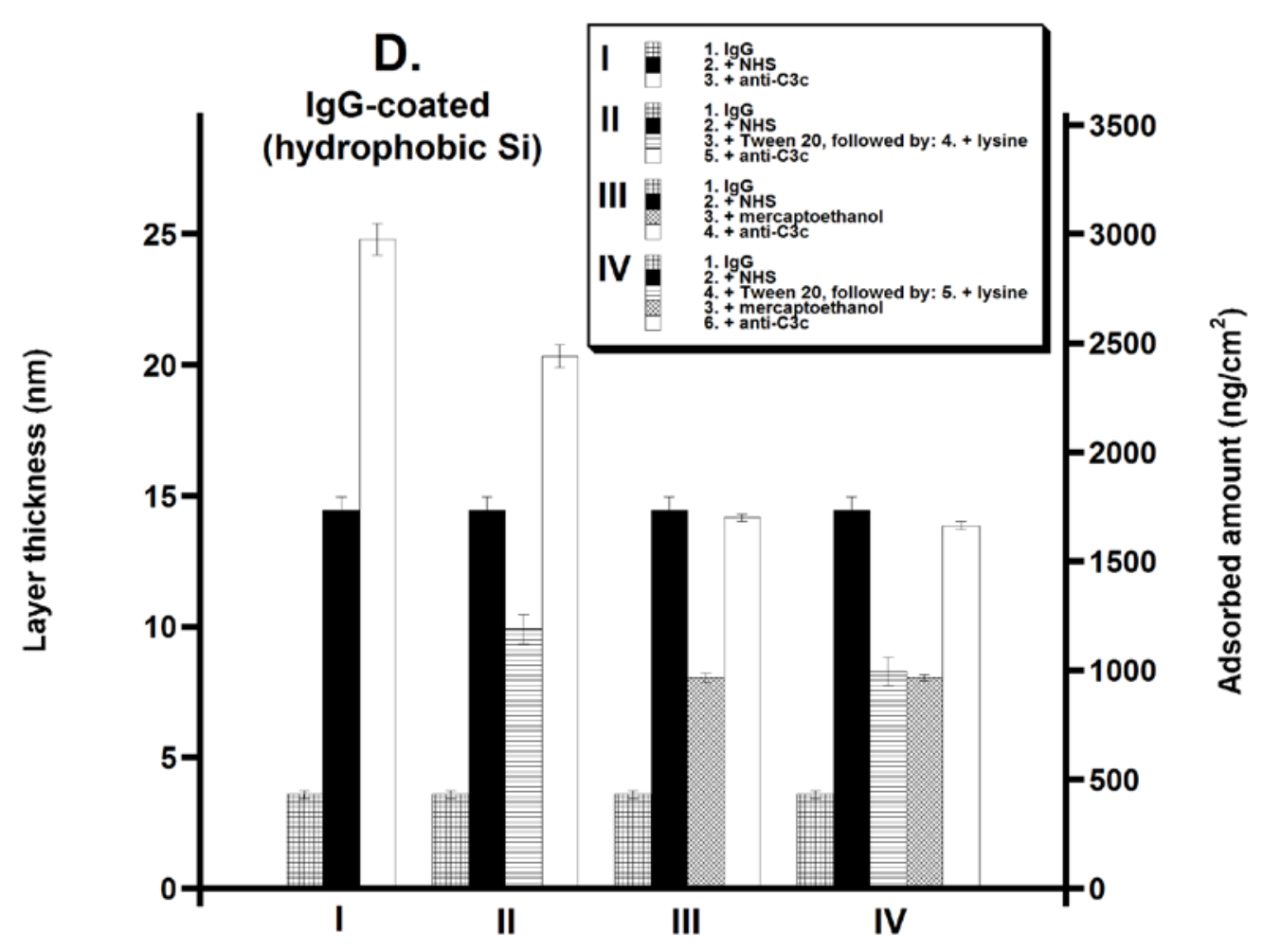


E. Elutability change with residence time

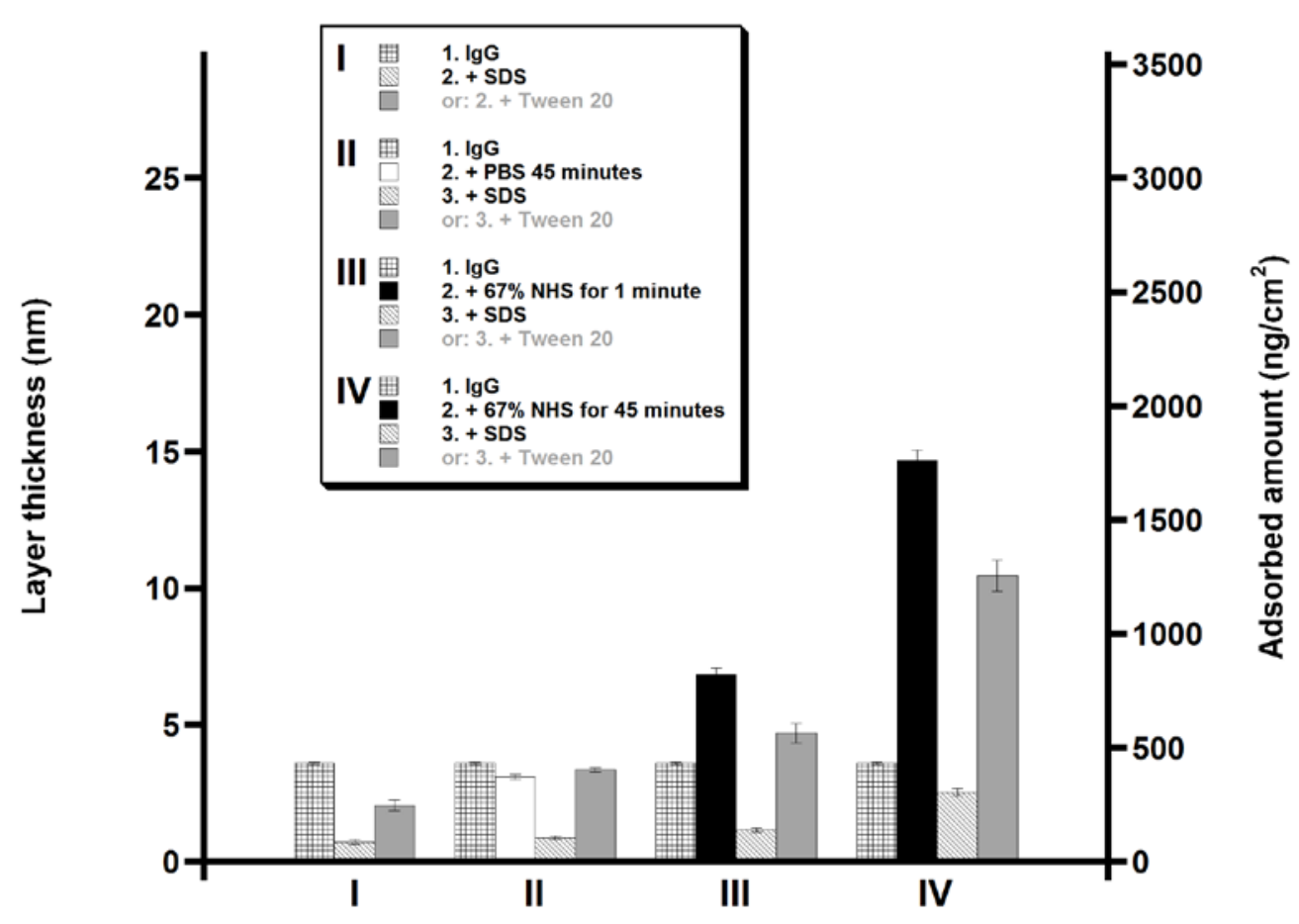


“Binding of complement to solids”-Wetterö et al.

\section{FIGURE 4}




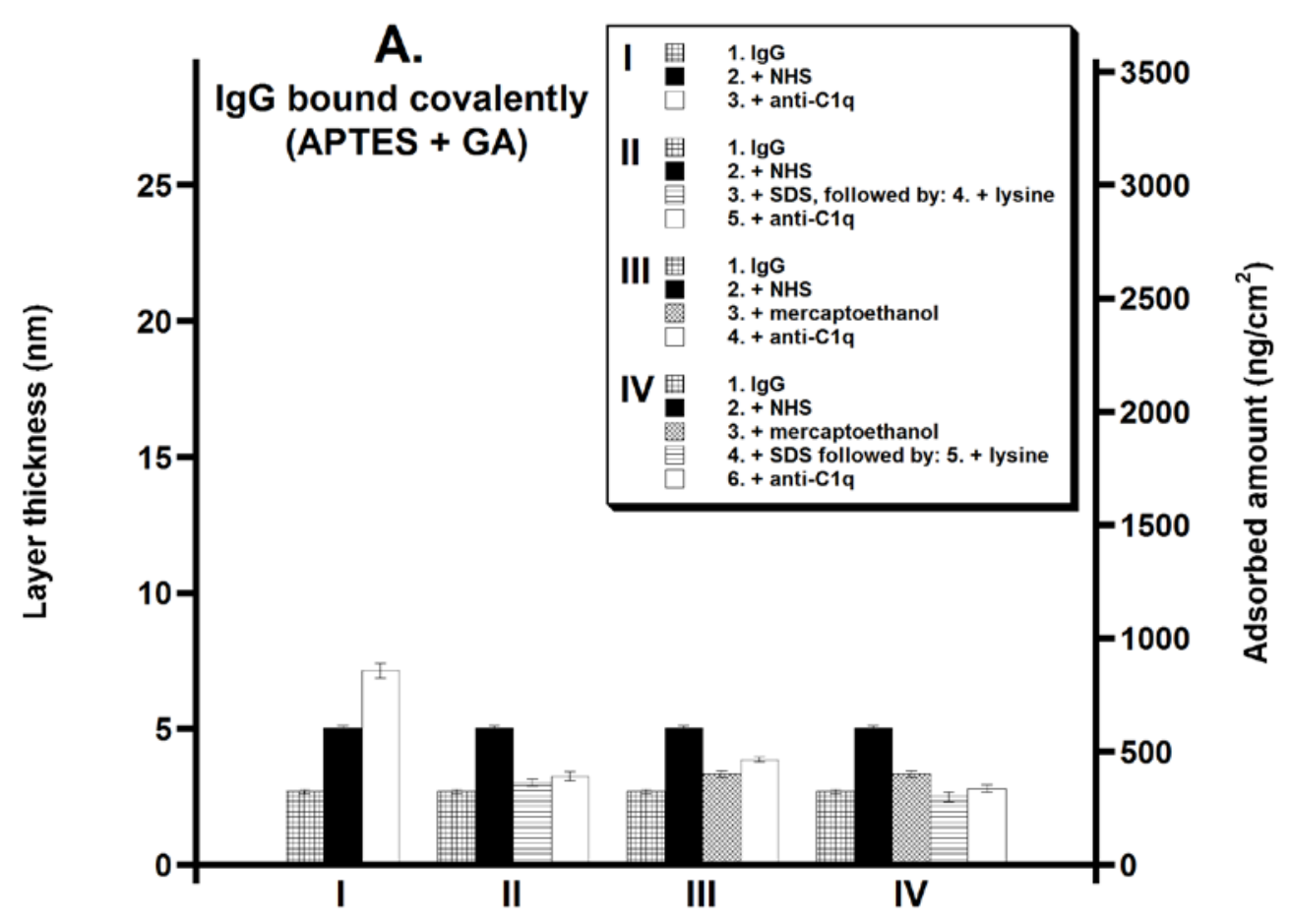




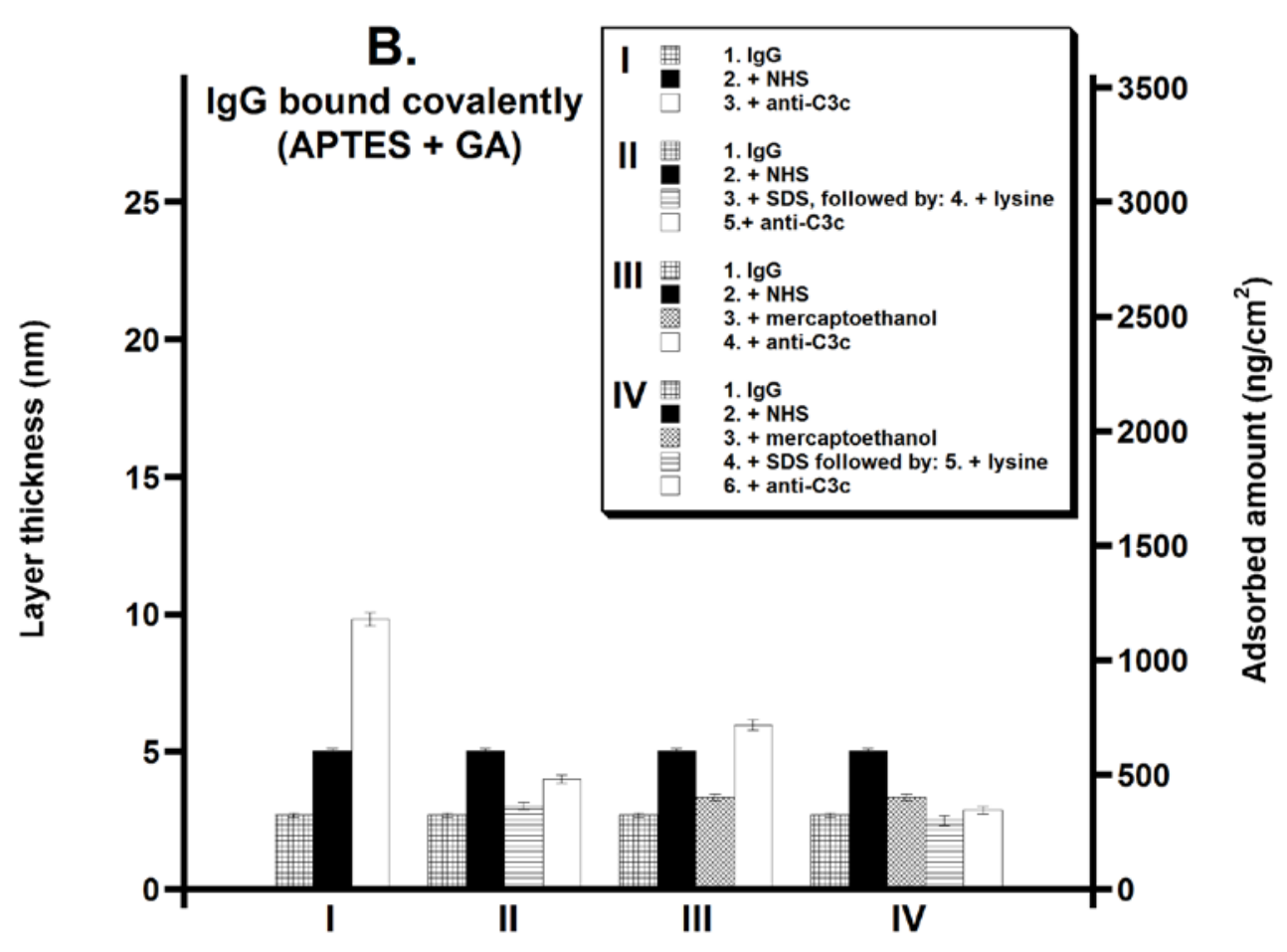




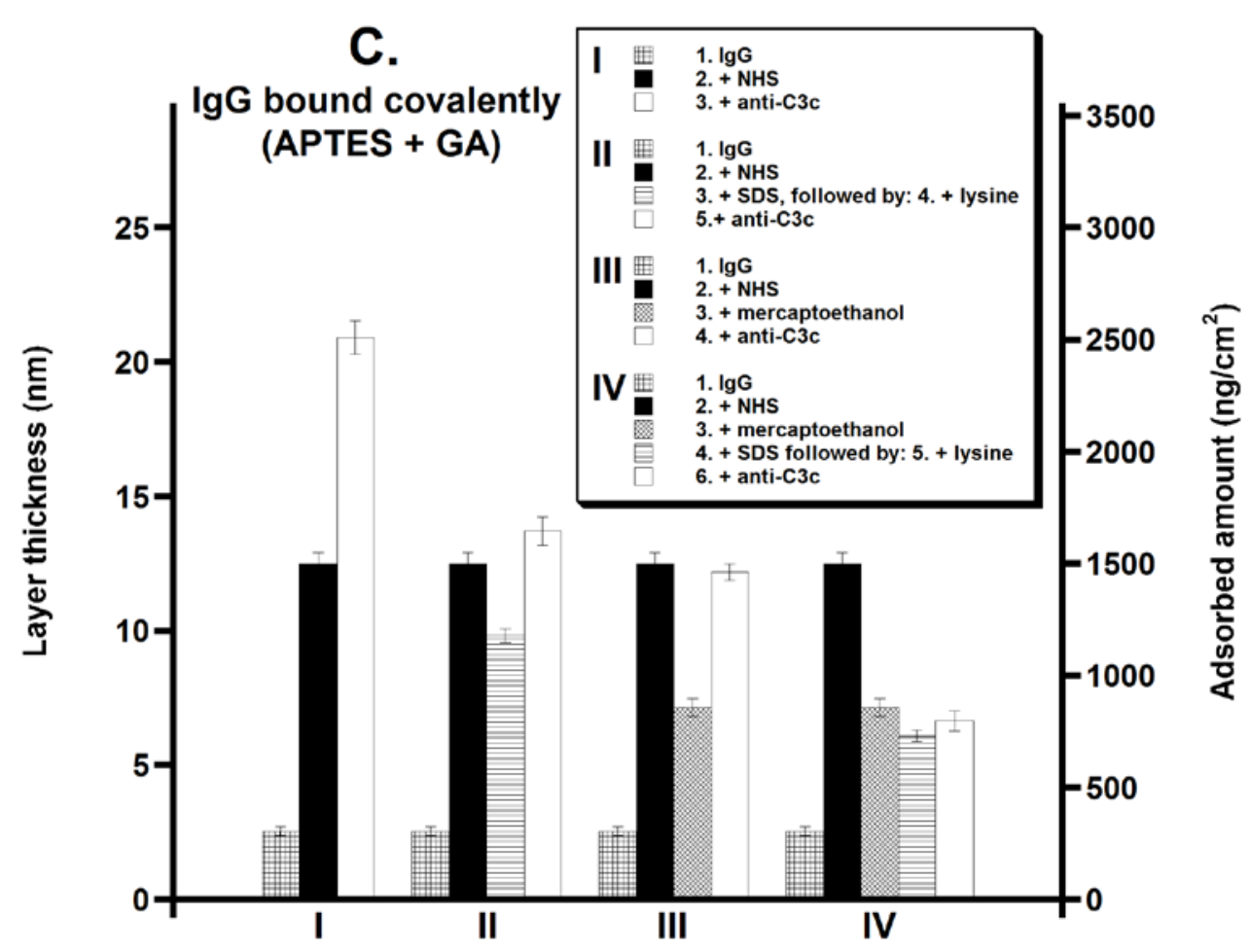




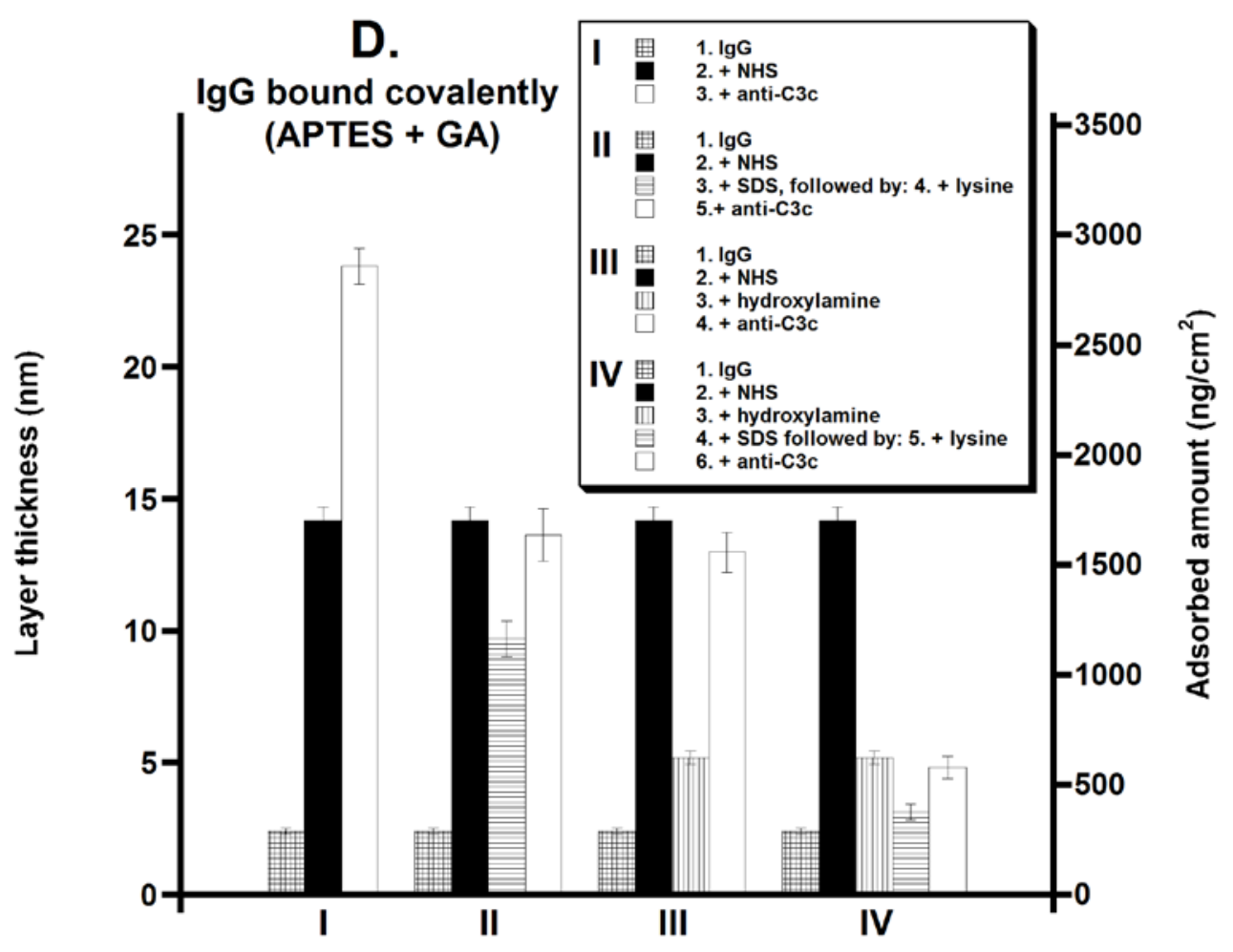

